\title{
Clinical Profile of Children with Pleural Effusion Admitted In a Tertiary Care Hospital of Bangladesh
}

\author{
Hasan $\mathrm{M}^{1}$, Islam $\mathrm{MR}^{2}$, Matin $\mathrm{A}^{3}$, Khan $\mathrm{R}^{4}$, Rahman $\mathrm{M}^{5}$, Islam $\mathrm{MR}^{6}$, Karim $\mathrm{AKMR}^{7}$
}

\begin{abstract}
Background: Pleural effusion is a problem commonly encountered by chest physicians. Objective: This study was an attempt to know the clinical presentation in order to avoid delay in diagnosis that may influence treatment and outcome. Methods: This cross-sectional study of thirty (30) admitted cases with pleural effusion were confirmed by chest radiography and aspiration of pleural fluid from one (1) year to twelve (12) years age of either sex the patientdwere selected purposively, was studied from July 2009 to Feb 2010 in the Department of Pediatrics, Rajshahi Medical College Hospital . All information were recorded in pre tested semi structured questionnaire. Results: Positivity was higher in male children, (66.7\%). Completely immunized were $56.7 \%$. One third of cases were severely malnourished. History of respiratory distress \& fever was present in $96.7 \%$, cough in $90 \%$. All cases had diminished chest movement, sub costal recession, and diminished breath sound on the affected side. Lobar consolidation was observed in $33.3 \%$ cases, patchy opacities in $53.3 \%$ cases. Fluid levels were observed in $76.7 \%$ cases. Color of pleural fluid was straw in $56.7 \%$, clear in $30.0 \%$, blood stained in $13.3 \%$. Conclusion: History and good clinical examination can diagnose pleural effusion.
\end{abstract}

Key words: pleural effusion, respiratory distress, Para pneumonic effusion.

\section{Introduction}

Pleural effusion is a problem commonly encountered by chest physicians, accounting for approximately $4 \%$ of all attendances to the chest clinic ${ }^{1}$. Pleural effusions are accumulations of fluid within the pleural space. The fluid enters the pleural space from systemic capillaries in the parietal pleura and exits via parietal pleural stomas and lymphatics. Pleural fluid accumulates when too much fluid enters or too little fluid exits the pleural space. They are classified as transudates or exudates. Detection of pleural effusion is done by physical examinations, chest X-ray \& thoracentesis. Asymptomatic transudates require no treatment. Symptomatic transudates and almost all exudates require thoracentesis, chest tube drainage, pleurodesis, pleurectomy or a combination ${ }^{2}$.

In various study it has been reported that, incidence of parapneumonic effusion ranges from $20 \%$ to $91 \%$ with an increase in morbidity and mortality ${ }^{3}$. Incidence of childhood empyema increased in UK in the mid to late $1990^{4}$. Parapneumonic effusion is more common in boys than girls and more frequently encountered in infants and young children ${ }^{5}$. Non bacterial infectious agents such as virus and Mycoplasma pneumoniae are the common causes of pleural effusion in children throughout the world. The frequency of viral infection in children is much higher than bacterial infection, though bacteria are more likely than virus to causes pleural effusion. Around $20 \%$ of these infections can cause small and transient effusion which can resolve spontaneously ${ }^{6}$. In a study it has been found that out of 176 children with pulmonary tuberculosis, from Spain, 39 (22\%) patients had pleural effusion ${ }^{7}$. In a review of 74 patients with intrathoracic lymphomas, Chaginaud ${ }^{8}$ found pleural effusion in $10(71 \%)$ of 14 children with lymphoblastic lymphomas and in $7(12 \%)$ of 60 children with non-Hodgkins lymphoma.

It is justified to know the clinical presentation in order to avoid delays in diagnosis that may influence treatment and outcome. The aim of the present study was to know the clinical presentation in order to avoid delay in diagnosis that may influence treatment and outcome.

1. Dr. Mahmudul Hasan, OSD, Directorate General of Health Services (DGHS), Dhaka

2. Dr. Md. Rafiqul Islam, Associate Professor, Department of Pediatrics, Shaheed Suhrawardy Medical College and Hospital, Dhaka

3. Dr. Abdul Matin, Assistant Professor, Department of Pediatrics, Shaheed Suhrawardy Medical College and Hospital, Dhaka

4. Dr. Rita Khan, Medical Officer, National Institute of Cancer Research \& Hospital (NICR \& H), Mohakhali, Dhaka

5. Dr. Mosfika Rahman, Honorary Medical Officer, Dhaka Medical College \& Hospital (DMCH), Dhaka

6. Dr. Md. Reazul Islam, Trainee Medical Officer, Dhaka National Medical College \& Hospital, Dhaka

7. Dr. A. K. M. Rezaul Karim, Assistant Professor, Department of Pediatrics, OSD, Directorate General of Health Services (DGHS), Dhaka

Correspondence

Dr. Md. Rafiqul Islam MBBS, DCH, M. Phil (Int. Health), Associate Professor, Department of Pediatrics, Shaheed Suhrawardy Medical College and Hospital, Dhaka - 1207, Bangladesh, Email: rafiq.1956@yahoo.com, Mobile: +8801715067652 


\section{Methodology}

This cross-sectional study was conducted in the Department of Pediatrics at Rajshahi Medical College Hospital from July 2009 to Feb 2010. A total number of thirty (30) admitted patients with pleural effusion, confirmed by chest radiography and aspiration of pleural fluid of one (1) year to twelve (12) years age of either sex were selected purposively. The parents were explained about the purpose of the study. Both the written \& verbal consents were taken from the parents. When parents did not give consent for any particular case next case was selected. The exclusion criteria were very sick children, age below one year and above twelve years, previously treated pleural effusion cases, cases having any other chronic illness or co-morbid situation, parents don't give consent for the study. All information's were recorded in pre-tested semi-structured questionnaire. Ethical clearance was taken from institutional ethical committe.

\section{Result}

Age distribution of cases, $15(50 \%)$ were within 4 years, $10(33.3 \%)$ were between 4 to 8 years, $5(16.7 \%)$ were 8 to 12 years of age (Table-I).

Table-1 : Distribution of study population according to Age ( $n=30)$

\begin{tabular}{ccc}
\hline Age (years) & Number & Percentage \\
\hline $1-4$ & 15 & 50 \\
$4-8$ & 10 & 33.3 \\
$8-12$ & 5 & 16.7 \\
Total & $\mathbf{3 0}$ & $\mathbf{1 0 0}$ \\
\hline
\end{tabular}

Positivity was higher in male children, $66.7 \%$ and $33.3 \%$ of female children was positive (Fig-1).

\section{Figure 1: Sex distribution of the studied children}

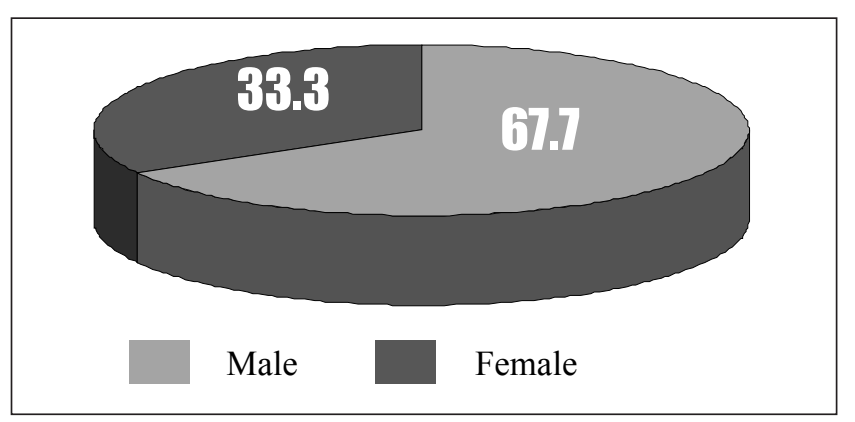

Completely immunized were $17(56.7 \%)$, partially immunized $10(33.3 \%)$, and $3(10 \%)$ were not given immunization.

Table-2 : Nutritional status among studied children $(n=30)$

\begin{tabular}{lcc}
\hline Status & Case & Percentage \\
\hline Severe & 12 & 40 \\
Moderate & 12 & 40 \\
Mild & 6 & 20 \\
Total & $\mathbf{3 0}$ & $\mathbf{1 0 0}$ \\
\hline
\end{tabular}

Nutritional status (according to WHO classification), $12(40 \%)$ cases were severely malnourished, $12(40 \%)$ were moderately and 6(20\%) were mildly malnourished (Table-II). Clinical presentation, history of respiratory distress \& fever was present in $29(96.7 \%)$, cough in $27(90 \%)$, and chest pain in $10(33.3 \%)$ cases (Table-III).

\section{Table-3 : Clinical presentation of studied children}

\begin{tabular}{lcc}
\hline Presenting Features & Case & Percentage \\
\hline Respiratory distress & 29 & 96.7 \\
Fever & 29 & 96.7 \\
Cough & 27 & 90 \\
Chest pain & 10 & 33.3 \\
\hline
\end{tabular}

Regarding physical signs, all (100\%) children had diminished chest movement, sub costal recession dull on percussion and diminished breath sound on the affected side, on the other hand. On the other hand $10(37 \%)$ cases had mediastinal shifting (Table-IV).

\section{Table-4 : Physical signs of studied children}

\begin{tabular}{lcc}
\hline Clinical signs & Number & Percentage \\
\hline Diminished chest movement & 30 & 100 \\
Sub costal recession & 30 & 100 \\
Dullness on percussion & 30 & 100 \\
Diminished breath sound & 30 & 100 \\
Mediastinal shifting & 10 & 37 \\
\hline
\end{tabular}

\section{Discussion}

In this study male cases were more, probably due to greater attention to the male children. A study found that parapneumonic effusions are more common in boys than girls and most frequently encountered in infants and young children $^{5}$. Yilmaz et $\mathrm{al}^{9}$ showed that the malnutrition was a common association with effusion in children. Here two fifth cases was severely malnourished. In this study fever, respiratory distress and cough were predominant presenting features. Restricted chest movement, subcostal recession, dullness on percussion and diminished breath

Table-5 : Site of pleural effusion among study population $(n=30)$

\begin{tabular}{lcc}
\hline Involvement & Number & Percentage \\
\hline Right side & 16 & 53.3 \\
Left side & 12 & 40 \\
Bilateral & 2 & 6.7 \\
\hline
\end{tabular}

sound were common physical findings. Presenting features were similar to another study done in Ethiopia ${ }^{10}$.

Barnes $^{11}$ found that $96 \%$ of the cases were diagnosed by ultrasonography though in this study, X-ray chest and 
thoracentesis were the main diagnostic tools for the diagnosis.

\section{Conclusion}

This study concluded that most of the children were malnourished. Fever, cough, respiratory distress and chest pain were the common presentations. Physical findings of effusion were present in all cases. Right sided pleural effusion was more than the left sided. History and good clinical examination can diagnosis pleural effusion.

\section{References}

1. Dev D, Basran Gs Pleural effusion: A clinical review, Monalde. Ach Chest Dis 1994; 49: 25-35.

2. Pleural Effusion: Mediastinal and Pleural Disorders: Merck Manual http://www.merck.com/mmpe/sec05/ch060/ch060d (access on 6/24/2010). 3. Moreira GDO, Ribeiro JD, Tresoldi ATZ. Utility of a scoring system \& indicative variables of assessing the neck for pleural drainage in peadiatrics patients with parapneumonic pleural effusion, Journal Brasileiro de Pneumologia. 2005; 31: 205-211.

4. Saglari S, Harries KA. Empyema: The use of broad range $16 \mathrm{~S}$ rDNA PCR for pathogen detection. Chest 2004; 155: 26-30.

5. Freij BJ, Kusmiesz H, Nelson JD parapneumonic effusion and empyema in hospitalized children; a retrospective review. AJR 1984; 3: 578-91.

6. Hendren WH. Haggery RJ. Staphylococcal pneumonia in infancy and childhood. JAMA 1958; 168:6-16.

7. Merino JM, Carpintero I, Alverz T, et al. Tuberculosus pleural effusion in children. Chest 1999; 115: 26-30.

8. Chaginaud BE, Bansack TA, et al. Pleural effusion in lymphoblastic lymphoma a diagnostic alternative. J Pediatr Surg 1998; 33: 1355-7.

9. Yilmaz E, Dagon Y, Aydinoglu AH, et al. Parapneumonic empyema in children: Conservative approach. Turk J Pediatr 2002; 44:138-8.

10. Hailu S. Pediatric thoracis empyema in an Ethiopian referral hospital. East Afr Med J 2000; 77: 618-21.

11. Barnes NP, Hull J, Thomson AH. Medical management of parapneumonic pleural disease. Pediatric Pulmonology 2005;39:127-136. 